\title{
Evolução da Produtividade do Trabalho e da Terra na Cafeicultura Baiana: Uma Análise Comparativa entre os Anos Censitários 2006 e 2017
}

\author{
Maíra Ferraz de Oliveira Silva ${ }^{1}$ (D) | Mônica de Moura Pires ${ }^{2}$ (D) | Fernando Salgueiro \\ Perobelli $^{3}$ iD | Andréa da Silva Gomes ${ }^{4}$ iD \\ ${ }^{1}$ Professora Assistente na Universidade Estadual do Sudoeste da Bahia. Aluna de doutorado na Universidade \\ Estadual de Santa Cruz. E-mail: mairaferraz@uesb.edu.br \\ ${ }^{2}$ Universidade Estadual de Santa Cruz. E-mail: mpires@uesc.br \\ ${ }^{3}$ Universidade Federal de Juiz de Fora. E-mail: fernandosalgueiro.perobelli@gmail.com \\ ${ }^{4}$ Universidade Estadual de Santa Cruz. E-mail: asgomes@uesc.br
}

\begin{abstract}
RESUMO
Este artigo apresenta a evolução da produtividade do trabalho e da terra para a cafeicultura baiana e identifica os fatores relevantes para o seu crescimento. Os dados, em nível de municípios, foram extraídos dos Censos Agropecuários dos anos de 2006 e 2017 do IBGE, para as variáveis: Valor bruto da produção de café, Pessoas ocupadas na cafeicultura, Superfície cultivada com café e Superfície agrícola municipal. Os resultados apontam redução do pessoal ocupado na atividade entre 2006 e 2017, maior concentração da renda per capita gerada nos municípios produtores da região do Cerrado, tendo o Planalto e o Atlântico como as áreas com cultivos de café mais relevantes na Bahia. O crescimento da produção no Cerrado ocorre em função de fatores intensivos em capital e nas outras regiões pelo uso intensivo do fator terra. Verifica-se uma heterogeneidade na produtividade da cafeicultura baiana e condicionantes distintos entre 2006 e 2017 .
\end{abstract}

\section{PALAVRAS-CHAVE}

Pessoal ocupado, Superfície agrícola, Produção de café

Evolution of the Land and Labor Productivity of Bahia Coffee Farming: A Comparative Analysis between the 2006 and 2017 Censuses

\begin{abstract}
This article presents the evolution of the land and labor productivity of Bahia coffee farming and identifies important factors for its growth. The data are at the level of municipalities have been extracted from the agricultural census of 2006 and 2017 of the IBGE, examined by variables: Gross value of coffee production, Persons employed in activity, Area under coffee cultivation and Municipality's agricultural area. The results reveal decline of the staff employed in the activity between 2006 and 2017, greater concentration of per capita generated the municipalities situated in the Cerrado region, having as Planalto and Atlântico such as coffee production áreas most relevant in Bahia. The growth of production in Cerrado occurs due to capital-intensive factors, and in other regions there is an intensive use of land factor. There is a heterogeneity in Bahia coffee productivity and distinct conditions between 2006 and 2017.
\end{abstract}

\section{KEYWORDS}

Personnel employed, Agricultural area, Coffee production

\section{CLASSIFICAÇÃO JEL}

$\mathrm{R} 14$ 


\section{Introdução}

A Bahia, unidade federativa situada ao sul da região Nordeste do Brasil, tendo a capital sediada em Salvador, possui uma área de 564.733,17 $\mathrm{km}^{2}$ e uma população de 14.016.906, segundo dados do Censo Demográfico de 2010, composta por 417 municípios, e densidade demográfica de $24,8 \mathrm{hab} / \mathrm{km}^{2}$.

A produção baiana de café, distribuída entre diversos municípios entre diferentes regiões do estado, situa-se na quinta posição entre os mais importantes produtores do Brasil e as especificidades de seu território geram diversidade de qualidade do produto, revelando potencial de novos mercados do café. Essas distinções, resultado de uma produção difusa sobre o território baiano, tornam singular a Bahia no mercado cafeeiro nacional.

Os cultivos de café na Bahia vêm passando por avanços, resultado, em parte, da modernização da agricultura brasileira e da proximidade com importantes estados produtores de café, como Minas Gerais e Espírito Santo, conforme apontam Ormond et al. (1999), muito embora ainda conservadores e concentrados no segmento familiar de produção, de acordo com os dados do Censo Agropecuário do IBGE para o ano de 2017. Do total de estabelecimentos agropecuários dedicados à cafeicultura no estado da Bahia, $72 \%$ são classificados como agricultura familiar e $28 \%$ como não familiar, porém, em termos de área, esses percentuais se invertem, pois o segmento familiar ocupa $27,3 \%$ da área total e o segmento não familiar, $72,7 \%$.

Sob a ótica da análise espacial da cafeicultura brasileira, a literatura recente evidencia um conjunto de estratégias metodológicas, conforme trabalhos de Barros et al. (2019); Volsi et al. (2019); Moreira et al. (2019), que utilizaram diferentes abordagens como a Análise Exploratória de Dados Espaciais (AEDE), econometria espacial, coeficientes de correlação, análises de agrupamento e medidas de especialização e localização, para compreender a dinâmica de distribuição e produtividade do café, além da especialização e crescimento da atividade nas principais regiões produtoras do país, inclusive no estado da Bahia, e, mais recentemente, os trabalhos de Ferrão et al. (2019); Cardozo et al. (2019); Bernardes (2019), os quais realizaram análise espacial sobre a produtividade da cafeicultura para o Espírito Santo, na Região Sudeste e em Minas Gerais, respectivamente, utilizando a AEDE, o índice de Moran e a econometria espacial.

De forma geral, todos esses estudos apontaram para a presença de autocorrelação espacial e convergência espacial da produção e produtividade entre as regiões produtoras de café analisadas. Verificaram ainda alterações na configuração de especialização e localização de clusters de produtividade em decorrência do cenário socioeconômico e ambiental (especialmente o clima) das regiões produtoras.

Na literatura internacional, parte dos estudos centram-se na análise da produtividade do setor cafeeiro a partir da estimação dos determinantes de produtividade, 
a exemplo de estudos realizados por Nurhapsa et al. (2020); Prasad et al. (2019); Temesgen e Tufa (2017) na Indonésia, Nepal, Luanda e Etiópia, respectivamente, utilizando, principalmente, modelos de regressão linear múltipla tomando por base teórica a função Cobb-Douglas. Esses autores verificaram que culturas consorciadas e sombreadas com café, densidade de plantio, acesso à irrigação, experiência na atividade, posse de veículos, participação em programas de treinamento relacionados à produção e comercialização, fertilizantes, tamanho da fazenda, mão de obra familiar são fatores relevantes na determinação da produtividade do café. Em contrapartida, constataram que tamanho da área, número de árvores produtivas, custos de mão de obra, gênero, idade do produtor, pouca disponibilidade de mão de obra, dificuldade ou falta de acesso a serviços de extensão, baixa inclusão de jovens na produção, preço recebido pelo produtor e receita gerada com a produção são fatores caracteristicamente inelásticos à produtividade de café. Destaca-se que a classificação de alguns desses fatores (tamanho da área e número de árvores produtivas) como inelásticos foi associada à ineficiência produtiva dos produtores, na Indonésia.

Ao aplicarem a análise de fronteira estocástica com enfoques sobre custo-benefício e eficiência técnica, para a realidade de países como Vietnam, Ruanda, Costa Rica e Camarões, os autores Anh et al. (2019); Ngango e Kim (2019); Wollni e Brümmer (2012); Nchare (2007) constataram, de forma geral, elevados índices de eficiência técnica entre os cafeicultores em função de fatores como nível educacional do agricultor e acesso ao crédito e extensão rural como as principais variáveis socioeconômicas para delinear maiores índices.

Nesse contexto, surgem questionamentos acerca de quais são os efeitos da dinâmica de uso dos fatores trabalho e terra e como tais fatores afetam a produtividade da cultura cafeeira nas diferentes regiões produtoras do estado da Bahia.

A especificidade da distribuição dos fatores produtivos e a dinâmica de evolução das variáveis que condicionam a produtividade da cultura podem ter efeitos diversos sobre os municípios produtores, determinando estratégias diferenciadas de inserção no mercado cafeeiro local e global. Dessa forma, compreender esses elementos e particularidades das regiões dedicadas à cafeicultura torna-se relevante para entender a dinâmica produtiva e promover a criação de estratégias de inserção nos mercados regionais, nacionais e mundiais, consolidando o posicionamento da Bahia no mercado cafeeiro.

Diante do exposto, este artigo tem como objetivo apresentar a evolução da produtividade do trabalho e da terra na cafeicultura baiana, a fim de identificar os fatores mais relevantes no crescimento da produção cafeeira. Para isso, foram utilizados dados do Censo Agropecuário realizado pelo Instituto Brasileiro de Geografia e Estatística (IBGE), para analisar a produtividade do trabalho (pessoas ocupadas na atividade) e da terra (superfície agrícola) na cafeicultura dos municípios baianos relativos aos anos censitários de 2006 e 2017. 


\section{Contextualização regional e caracterização da cafeicul- tura baiana}

O café é uma das principais commodities negociadas mundialmente e é oriundo de países em desenvolvimento, sendo a receita gerada pela sua exportação uma importante fonte de divisas desses países. Na produção mundial de café, o Brasil tem mantido a posição de liderança, embora outros países tenham ingressado no mercado, com participações menores, porém com taxas de crescimento anual maiores (Figuras la e $1 b)$.

Conforme Figura 1a, verifica-se que o comportamento da produção mundial se assemelha ao do Brasil, haja vista que o país participa, em média, com $48 \%$ do total da produção mundial no período 1990-2017 (Figura 1b). Ao longo de todo esse período, o Brasil manteve sua liderança no mercado, apontando para a importância do país no comércio internacional de café.

Figura 1. Evolução (a) e participação (b) da produção brasileira e mundial e de café, em mil sacas de $60 \mathrm{~kg}$, período 1990-2017
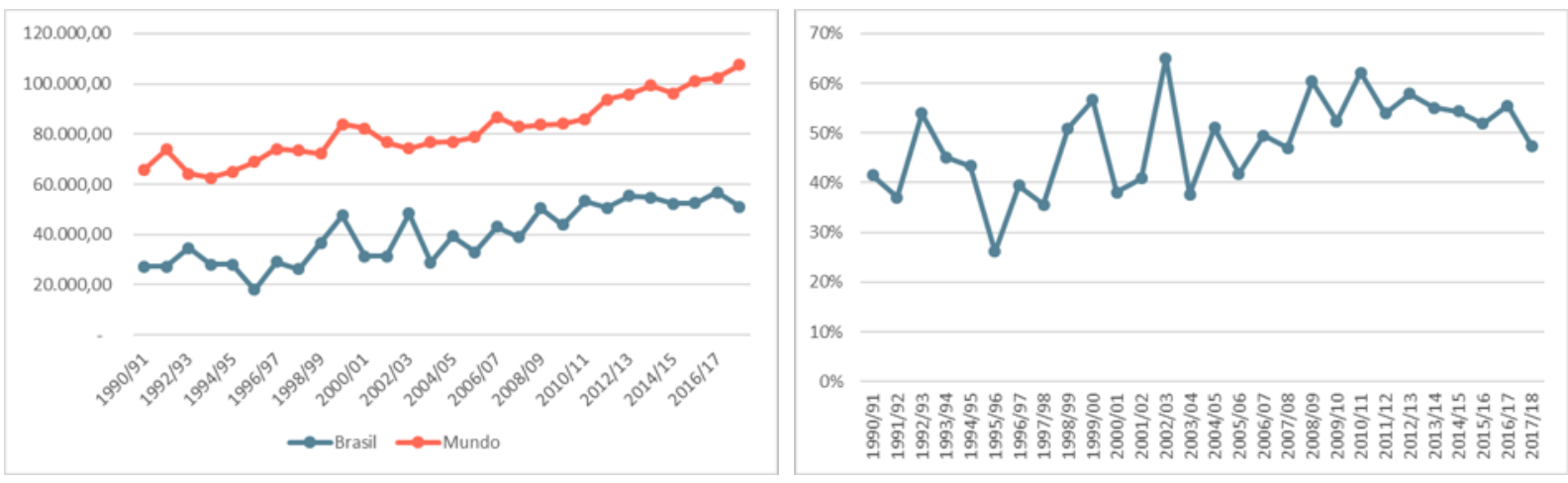

Fonte: Elaboração própria a partir de dados da Organização Internacional do Café (OIC).

Na Tabela 1, apresentam-se os 12 países com maior média de produção no período de 1990-2017 e a evolução de crescimento no período e nos subperíodos. Nota-se que, à exceção de Colômbia e Costa do Marfim, todos os demais países apresentaram crescimento da produção entre 1990 e 2017. Porém, nos quatro subperíodos analisados, a maioria tem declínio na produção. Nas taxas negativas, Vietnã e Peru apresentam os maiores decréscimos.

Ao tratarem da recente evolução da produção cafeeira mundial em um cenário de novas tendências no consumo do café, Saes e Nakazone (2002) referem-se ao desenvolvimento de nichos de mercado, em particular de qualidade superior, e de uma nova perspectiva no que se refere à inserção para pequenos e médios cafeicultores.

Isto condiz com a estratégia de expansão do mercado de consumo interno de café no Brasil. De acordo com esses autores, nas últimas décadas, o País, sendo o maior produtor e um dos maiores consumidores de em nível mundial, apresenta situação 
amplamente favorável à promoção do consumo de cafés de qualidade superior, acompanhando a nova tendência mundial de nicho, em especial de bebidas à base de café.

Tabela 1. Principais países produtores de café, média de produção no período em mil sacas de $60 \mathrm{~kg}$ e taxas de crescimento por períodos entre os anos de 1990 e 2017

\begin{tabular}{|c|c|c|c|c|c|c|}
\hline Países & $\begin{array}{r}\text { média } \\
1990-2017 \\
\text { (mil sacas) }\end{array}$ & $\begin{array}{r}1990 / 96 \\
(\%)\end{array}$ & $\begin{array}{r}1997 / 03 \\
(\%)\end{array}$ & $\begin{array}{r}2004 / 10 \\
(\%)\end{array}$ & $\begin{array}{r}2011 / 17 \\
(\%)\end{array}$ & $\begin{array}{r}1990 / 17 \\
(\%)\end{array}$ \\
\hline Brasil & 36.079 & $-7 \%$ & $-10 \%$ & $-36 \%$ & $-1 \%$ & $87 \%$ \\
\hline Vietnã & 13.225 & $-339 \%$ & $-120 \%$ & $-39 \%$ & $-11 \%$ & $2151 \%$ \\
\hline Colômbia & 10.701 & $25 \%$ & $8 \%$ & $26 \%$ & $-83 \%$ & $-2 \%$ \\
\hline Indonésia & 7.596 & $-10 \%$ & $16 \%$ & $-21 \%$ & $-58 \%$ & $47 \%$ \\
\hline Etiópia & 4.321 & $-17 \%$ & $-44 \%$ & $-44 \%$ & $-13 \%$ & $163 \%$ \\
\hline Índia & 4.032 & $-21 \%$ & $-18 \%$ & $-10 \%$ & $-12 \%$ & $106 \%$ \\
\hline México & 3.945 & $-9 \%$ & $13 \%$ & $-3 \%$ & $12 \%$ & $-14 \%$ \\
\hline Guatemala & 3.531 & $-38 \%$ & $14 \%$ & $-7 \%$ & $1 \%$ & $16 \%$ \\
\hline Honduras & 3.191 & $-28 \%$ & $-16 \%$ & $-68 \%$ & $-42 \%$ & $432 \%$ \\
\hline Uganda & 2.869 & $-75 \%$ & $24 \%$ & $-25 \%$ & $-64 \%$ & $161 \%$ \\
\hline Peru & 2.598 & $-93 \%$ & $-39 \%$ & $-19 \%$ & $20 \%$ & $357 \%$ \\
\hline Costa do Marfim & 2.407 & $-65 \%$ & $28 \%$ & $61 \%$ & $41 \%$ & $-56 \%$ \\
\hline Total mundial & $121.724,98$ & & & & & \\
\hline Desvio-padrão & $22.749,04$ & & & & & \\
\hline Menor valor & $87.056,47$ & & & & & \\
\hline Maior valor & $159.047,09$ & & & & & \\
\hline Coef. de variação & 0,19 & & & & & \\
\hline
\end{tabular}

Fonte: Elaboração própria a partir de dados da Organização Internacional do Café (OIC).

Destacam que as novas tendências de consumo em âmbito mundial inserem-se na lógica recente de organização da atividade econômica em nível internacional, que implica a evolução do processo de dispersão geográfica das atividades econômicas para além das fronteiras nacionais acompanhada do recente fenômeno de integração funcional entre atividades dispersas internacionalmente, vulgarmente conhecido pelo termo "globalização". Saes e Nakazone (2002) esclarecem ainda que essa integração funcional se efetiva por meio da atuação das empresas multinacionais, verticalizadas ou não, e de sua interação com outras empresas e agentes econômicos de diversos segmentos que compõem determinada atividade produtiva. 
A delimitação dos mercados locais e globais do café é definida pela espécie da planta e pela qualidade intrínseca ao produto, enquanto o dinamismo está associado ao volume produzido e comercializado. A qualidade do café está associada às condições ambientais, estruturais e tecnológicas das regiões de cultivo. No aspecto ambiental, o fator determinante da qualidade depende da espécie e dos tratos culturais adotados (IBGE, 2016). Ademais, entre as espécies de maior interesse econômico estão Coffea arábica e Coffea canéfora (conhecida como robusta ou conillon), que representa cerca de $70 \%$ e 30\%, respectivamente, da produção mundial.

A regionalização das zonas produtoras, também definida por condições ambientais específicas para cada espécie, segundo Neto (2010), são essenciais para a compreensão da distribuição da produção de café entre os países produtores, gerando os denominados "Cinturões de Café"nas Américas Central e do Sul, África e na Ásia.

Essas regiões abrangem países localizados na faixa entre os Trópicos de Câncer e de Capricórnio, sendo majoritário o cultivo da espécie arábica em territórios de altitude acima de 500 metros e mais próximos da linha do Equador. Para o autor, a diversidade característica da cafeicultura associada aos aspectos geográficos confere um "vasto mundo do café", pois

Devido à sua característica genética, grãos de arabica apresentam uma rica gama de notas de aroma e sabor, conferindo, ainda mais, a condição de "Produto de Terroir". Fatores como clima, posição geográfica e variedades empregadas, além do manejo feito pelo produtor, são decisivos na tipificação do produto. Simplesmente, cada grão de uma mesma variedade pode se expressar sensorialmente de forma diferente em cada origem. (...) Compreender que o café é um típico produto de "terroir"e verificar a extensão que o Cinturão Brasileiro de Café ocupa no alinhamento Norte-Sul, desde a Bahia até o Paraná, aqui em regiões subtropicais, permite inferir que um vasto mosaico de aromas e sabores podem ser encontrados nos Cafés do Brasil. Daí ser verdadeira a afirmação de que o Brasil "é um país com muitos sabores"(Neto, 2010).

No modelo da cafeicultura brasileira, sua produção agrícola esteve historicamente concentrada e localizada na região Sudeste, tendo sido mantida sua importância até meados da década de 1980. Porém, a partir de então, a produção se deslocou do eixo principal de São Paulo cedendo espaço para a crescente produção e especialização do estado de Minas Gerais e, ao mesmo tempo, aumentando também a participação do Espírito Santo no volume total nacional.

Os números da cafeicultura brasileira podem ser explicados pelo comportamento da produção da região Sudeste, pois o volume de produção dessa região representa mais de $4 / 5$ do total, alcançando cerca de $83 \%$ da produção em média do Brasil no período de 1990-2017. Porém, mais recentemente, os plantios de café vêm se expan- 
dido em direção ao Nordeste, em particular para o estado da Bahia, especialmente nas localidades fronteiriças com os estados de Minas Gerais e Espírito Santo.

Observa-se, na Tabela 2, que a Bahia figura entre os cinco maiores produtores com uma média de produção semelhante aos estados de Paraná e Rondônia e maior taxa de crescimento (43\%) no período de 1990-2017, superando o maior estado produtor do país (Minas Gerais). De maneira geral, os anos 2000 mostram crescimento da produção de café no Brasil, exceção para Espírito Santo e Paraná.

Tabela 2. Principais estados brasileiros produtores de café, média de produção no período em toneladas e taxas de crescimento por períodos entre os anos de 1990 e 2017

\begin{tabular}{lrrrrrrr}
\hline \hline & média & $1990-$ & $1990-$ & $1997-$ & $2004-$ & $2011-$ & \\
Unidades da federação & $1990 / 2017$ & 2017 & 1996 & 2003 & 2010 & 2017 & $\%{ }^{* *}$ \\
& $(\mathrm{~T})^{*}$ & $(\%)$ & $(\%)$ & $(\%)$ & $(\%)$ & $(\%)$ & \\
\hline Minas Gerais & 1.324 .737 & $40 \%$ & $28 \%$ & $-22 \%$ & $22 \%$ & $9 \%$ & $54 \%$ \\
Espírito Santo & 604.934 & $27 \%$ & $44 \%$ & $-7 \%$ & $20 \%$ & $-22 \%$ & $21 \%$ \\
São Paulo & 323.191 & $-60 \%$ & $-41 \%$ & $-50 \%$ & $8 \%$ & $10 \%$ & $10 \%$ \\
Paraná & 150.904 & $-79 \%$ & $-51 \%$ & $-46 \%$ & $-6 \%$ & $-39 \%$ & $3 \%$ \\
Bahia & 134.862 & $43 \%$ & $-39 \%$ & $63 \%$ & $18 \%$ & $6 \%$ & $6 \%$ \\
Rondônia & 124.487 & $-19 \%$ & $-40 \%$ & $41 \%$ & $39 \%$ & $60 \%$ & $5 \%$ \\
Brasil & 2.746 .749 & $-8 \%$ & $-7 \%$ & $-19 \%$ & $18 \%$ & $-0,6 \%$ & $100 \%$ \\
\hline \hline
\end{tabular}

Nota: ${ }^{*} \mathrm{~T}=$ tonelada. ${ }^{* *}$ Participação de cada estado no total do Brasil em relação ao ano de 2017.

Fonte: Elaboração própria a partir de dados da Pesquisa Agrícola Municipal do IBGE.

A produção baiana de café situa-se entre as cinco maiores no Brasil, como pode ser verificado na Tabela 2, e o principal fator que a diferencia dos demais estados produtores no país são as especificidades de seu território relativas às distintas condições edafoclimáticas, as quais permitem diversidade de qualidade e potencial no mercado do café.

A Companhia Nacional de Abastecimento (CONAB, 2014) realizou uma divisão regional das zonas cafeeiras da Bahia, com base na agregação por microrregiões consolidadas pelo IBGE, que compreende três principais aglomerados, denominados de Cerrado $^{1}$, Planalto ${ }^{2}$ e Atlântico ${ }^{3}$ (Figura 2).

\footnotetext{
${ }^{1}$ A zona cafeeira do Cerrado abrange as microrregiões de Barreiras, Cotegipe e Santa Maria da Vitória.

${ }^{2}$ A zona cafeeira do Planalto abrange as microrregiões de Boquira, Seabra, Jequié, Livramento do Brumado, Guanambi, Brumado, Vitória da Conquista e Itapetinga.

${ }^{3}$ A zona cafeeira do Atlântico abrange as microrregiões de Valença, Ilhéus-Itabuna e Porto Seguro.
} 
Figura 2. Zonas Cafeeiras do estado da Bahia e grupos de municípios que compõem os aglomerados da Chapada Diamantina e do Planalto da Conquista

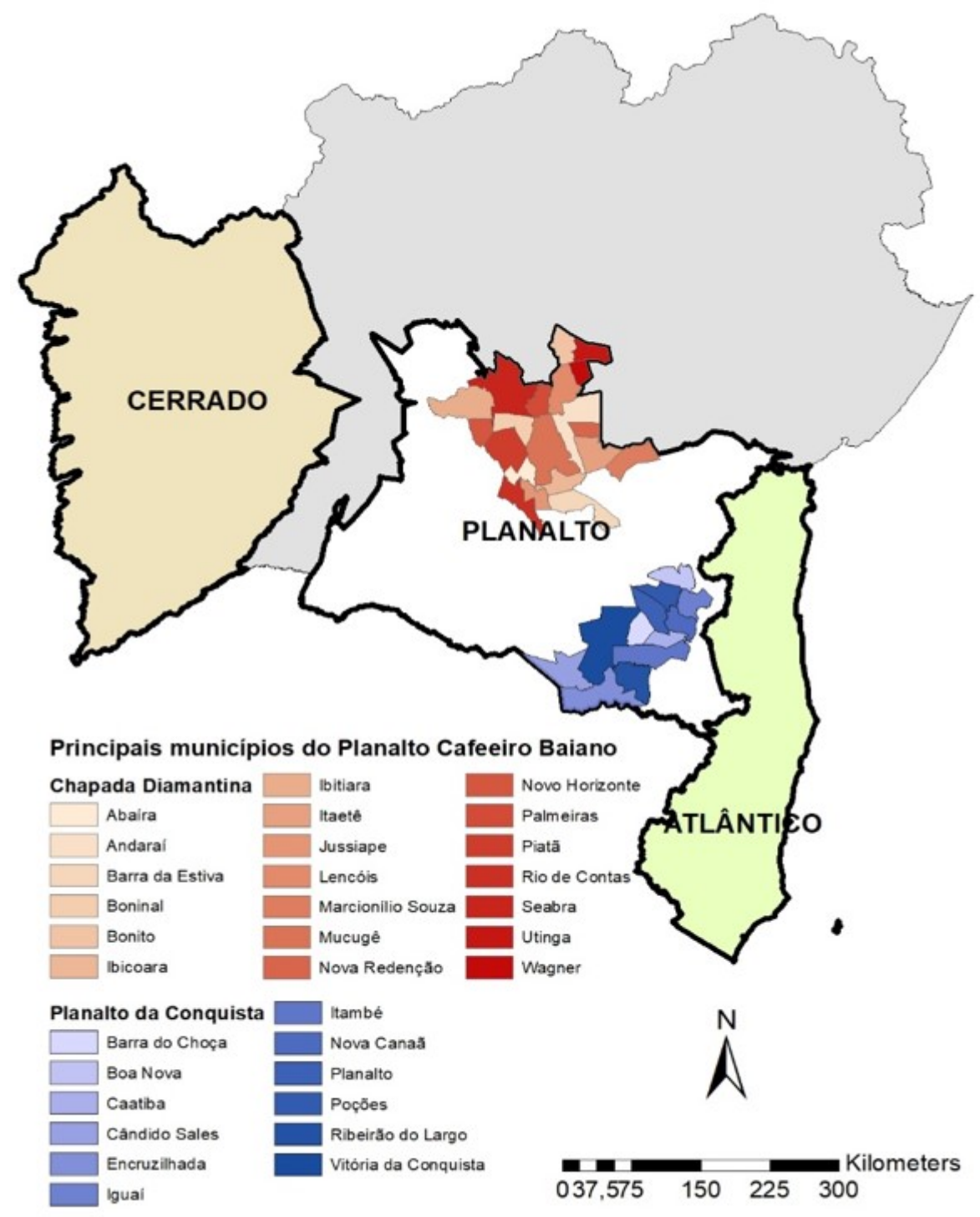

Fonte: Elaboração própria.

As zonas cafeeiras do Cerrado e Planalto são destinadas ao plantio do café arábica enquanto a região do Atlântico se dedica mais ao cultivo do café canephora (robusta ou conillon). Das zonas cafeeiras que se dedicam ao café arábica, o Cerrado, região oeste do estado, dedica-se a uma cafeicultura com alto nível tecnológico, enquanto as demais regiões praticam, em sua maioria, formas de cultivo mais tradicionais (Fernandes, 2014). Na zona do Planalto, duas delimitações regionais se destacam: um grupo de vinte e um entre os vinte e quatro municípios que compõem a Chapada Diamantina $^{4}$ e um grupo de doze municípios no entorno de Vitória da Conquista, locali-

\footnotetext{
${ }^{4}$ Composta pelos municípios de Abaíra, Andaraí, Barra da Estiva, Boninal, Bonito, Ibicoara, Ibitiara, Iraquara, Itaetê, Jussiape, Lençóis, Marcionílio Souza, Morro do Chapéu, Mucugê, Nova Redenção, Novo Horizonte, Palmeiras, Piatã, Rio de Contas, Seabra, Souto Soares, Utinga e Wagner (MDA, 2010). Esse
} 
zados na região sudoeste do estado, denominada de Planalto da Conquista ${ }^{5}$. Segundo Fernandes (2014), na Chapada Diamantina, predominam os cultivos orgânicos e, juntamente com a região do Planalto de Vitória da Conquista, a cafeicultura de altitude (e de montanha), bastante valorizada no mercado por suas características específicas, sobressaem-se na produção da zona cafeeira do Planalto.

Em termos da média de produção do período e considerando que os primeiros registros feitos pelo IBGE de produção de café no Cerrado ocorreram no ano de 1997 (Tabela 3), observa-se que o Planalto e o Atlântico apresentam médias superiores, visto que tradicionalmente praticam o cultivo há mais tempo.

Quanto às taxas de crescimento por períodos, verifica-se que as maiores taxas foram alcançadas no Cerrado entre os anos de 1997 e 2003 e uma dinâmica de taxas mais elevadas e positivas nos períodos finais na região do Atlântico, em detrimento da retração ocorrida no Planalto.

A Tabela 4 apresenta a média por período e as taxas de crescimento, utilizando como variável base o rendimento médio da produção em quilogramas por hectare. Essa variável pode evidenciar as diferenças regionais em termos de modelo produtivo e diferenças tecnológicas.

Nota-se que as médias de rendimento são superiores na região do Cerrado em relação ao Planalto e ao Atlântico, cujos valores são mais próximos e muito similares internamente, visto que essa região é considerada uma das mais modernas do estado no que diz respeito ao incremento tecnológico na produção agrícola concentrada em grandes latifúndios.

A proximidade e a similaridade entre as médias de rendimento das regiões do Planalto e do Atlântico mostram a realidade dos seus modelos produtivos mais tradicionais e a tendência de taxas de crescimento negativas no Planalto e positivas no Atlântico, que revelam a migração, nessa última região, para um modelo produtivo mais efetivo no sentido das adaptações tecnológicas voltadas ao segmento da pequena e média produção agrícola, predominante nessas regiões.

As mudanças na demanda global vêm promovendo adequação da estrutura produtiva e formas de articulação pelos produtores nas diversas atividades realizadas, condicionando o tipo de qualidade do café predominante nos diversos territórios e influenciando como esses produtores se inserem nos diversos mercados e daí na configuração territorial da cafeicultura brasileira e baiana.

grupo compõe os vinte e quatro municípios abrangidos pela Chapada Diamantina. Na delimitação da zona cafeeira do Planalto, excluem-se os municípios de Iraquara, Morro do Chapéu, Souto Soares e Tapiramutá.

${ }^{5}$ Composta pelos municípios de Vitória da Conquista, Barra do Choça, Planalto, Poções, Encruzilhada, Ribeirão do Largo, Itambé, Caatiba, Iguaí, Cândido Sales, Boa Nova e Nova Canaã (Silva, 2013). 
Tabela 3. Microrregiões do estado Bahia produtoras de café, média de produção no período em toneladas e taxas de crescimento por períodos entre os anos de 1990 e 2017

\begin{tabular}{|c|c|c|c|c|c|c|}
\hline \multirow{3}{*}{ Microrregião } & Média & 1990(1)- & 1990- & $1997-$ & 2004- & 2011- \\
\hline & $1990(1) / 17$ & 2017 & 1996 & 2003 & 2010 & 2017 \\
\hline & $(\mathrm{T})$ & (\%) & (\%) & $(\%)$ & (\%) & (\%) \\
\hline \multicolumn{7}{|l|}{ CERRADO } \\
\hline Barreiras & 19.119 & $828,8 \%$ & - & $2647,5 \%$ & $-8,4 \%$ & $-60,4 \%$ \\
\hline Cotegipe & - & - & - & - & - & - \\
\hline $\begin{array}{l}\text { Santa Maria } \\
\text { da Vitória }\end{array}$ & 3.627 & $13794,7 \%$ & - & $12292,1 \%$ & $-1,2 \%$ & $25,1 \%$ \\
\hline \multicolumn{7}{|l|}{ PLANALTO } \\
\hline Boquira & 15 & $-94,4 \%$ & $-44,4 \%$ & $73,3 \%$ & $7,1 \%$ & $-92,9 \%$ \\
\hline Seabra & 26.920 & $-17,5 \%$ & $-43,0 \%$ & $45,1 \%$ & $42,9 \%$ & $-46,0 \%$ \\
\hline Jequié & 12.576 & $-94,4 \%$ & $-64,8 \%$ & $26,2 \%$ & $-35,2 \%$ & $-83,5 \%$ \\
\hline $\begin{array}{l}\text { Livramento } \\
\text { do Brumado }\end{array}$ & 9 & $200,0 \%$ & $-100,0 \%$ & - & $25,0 \%$ & $-80,0 \%$ \\
\hline Guanambi & 365 & $-65,8 \%$ & $127,7 \%$ & $26,4 \%$ & $5,9 \%$ & $-86,2 \%$ \\
\hline Brumado & 2.065 & $-48,9 \%$ & $-100,0 \%$ & - & $61,3 \%$ & $13,7 \%$ \\
\hline Vitória da & 28.752 & $-63,2 \%$ & $-52,2 \%$ & $9,5 \%$ & $74,1 \%$ & $-37,6 \%$ \\
\hline Conquista & & & & & & \\
\hline Itapetinga & 5.811 & $79,9 \%$ & $124,5 \%$ & $-45,2 \%$ & $125,4 \%$ & $9,0 \%$ \\
\hline \multicolumn{7}{|l|}{ ATLÂNTICO } \\
\hline Valença & 532 & $153,8 \%$ & $-65,8 \%$ & $504,4 \%$ & $-4,1 \%$ & $-19,0 \%$ \\
\hline Ilhéus-Itabuna & 3.576 & $513,4 \%$ & $-15,1 \%$ & $177,0 \%$ & $-21,2 \%$ & $58,7 \%$ \\
\hline Porto Seguro & 29.516 & $2328,2 \%$ & $245,5 \%$ & $85,8 \%$ & $48,4 \%$ & $155,4 \%$ \\
\hline
\end{tabular}

Nota: (1) Para o cálculo da média do rendimento da produção por área e taxa de crescimento do período, considerou-se o ano inicial de 1997 para as microrregiões de Barreiras e Santa Maria da Vitória, visto que esse foi o primeiro ano com registro de produção de café para estas regiões.

Fonte: Elaboração própria a partir de dados da Pesquisa Agrícola Municipal do IBGE. 
Tabela 4. Microrregiões do estado Bahia produtoras de café, média do rendimento da produção por área no período em quilogramas por hectare e taxas de crescimento por períodos entre os anos de 1990 e 2017

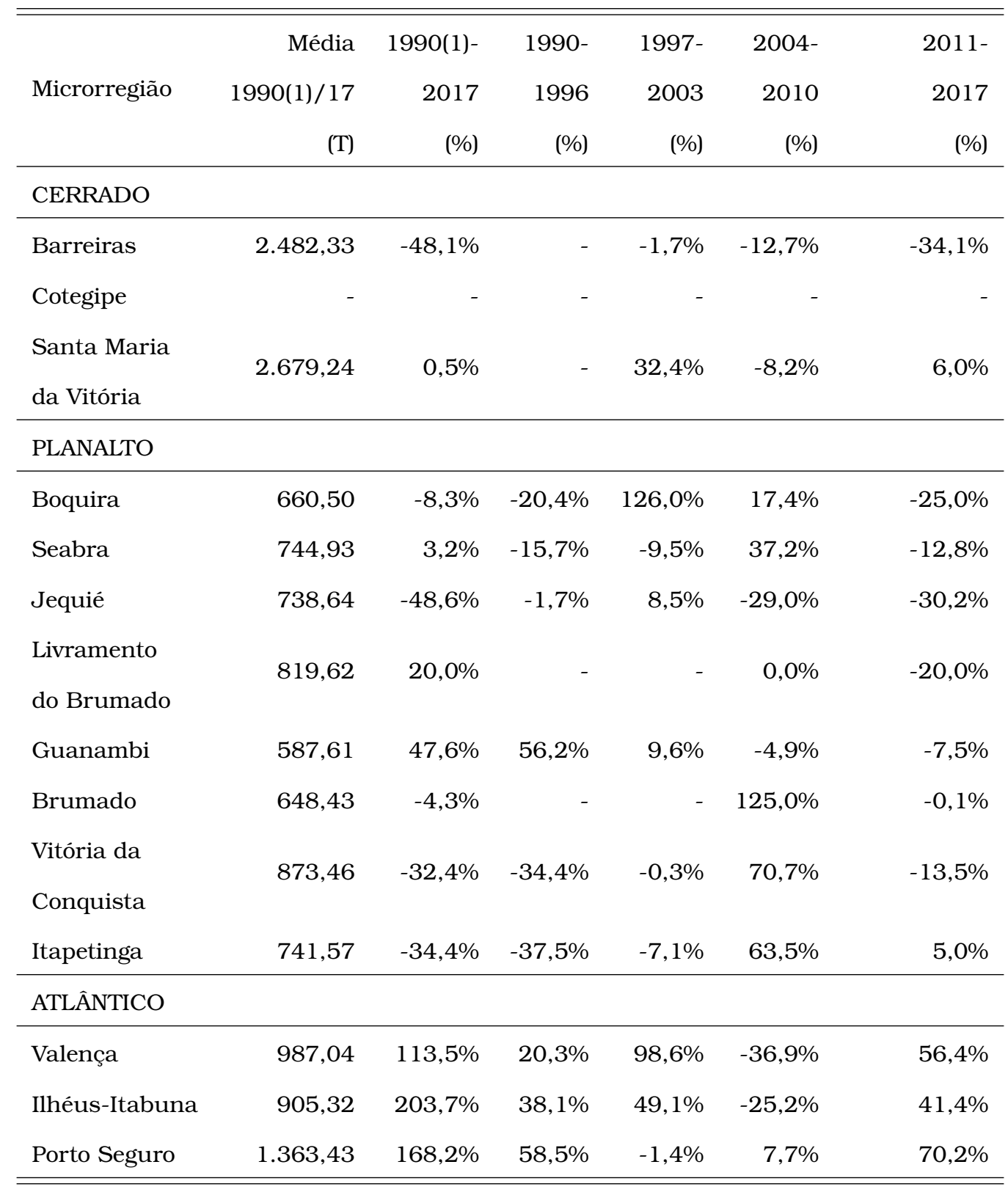

Nota: (1) Para o cálculo da média do rendimento da produção por área e taxa de crescimento do período, considerou-se o ano inicial de 1997 para as microrregiões de Barreiras e Santa Maria da Vitória, visto que esse foi o primeiro ano com registro de produção de café para estas regiões.

Fonte: Elaboração própria a partir de dados da Pesquisa Agrícola Municipal do IBGE.

A tendência recente de perda de participação no comércio mundial de café com a participação mais efetiva de outros países produtores indica que a evolução da produção brasileira de café tende a especializar-se em dois segmentos principais: o segmento não familiar de alto nível tecnológico voltado ao atendimento da produção do café tipo commodity e a pequena produção tradicional voltada aos nichos de mercado orgânico 
e gourmet. Neste aspecto, o estado da Bahia segue a tendência observada em nível nacional no que se refere à especialização da atividade cafeeira, apresentando distintas alternativas de inserção em mercados diferenciados, como nos nichos orgânico e gourmet, e de commodity. Além dessas classificações, no nicho denominado "Appellation Coffees" ${ }^{6}$, existem iniciativas em duas das principais regiões cafeeiras do estado (Cerrado e Planalto).

A este respeito, destacam-se estudos sobre o potencial para a indicação geográfica de procedência, na Bahia, dos cafés do Planalto de Vitória da Conquista, e a inclusão do café produzido da região oeste do estado no Mapa das Indicações Geográficas do Brasil, produzido pelo IBGE, após a concessão de indicação de procedência (IP) pelo INPI, reconhecendo essa região oeste como peculiar para a produção café verde em grãos em condições climáticas diferenciadas ${ }^{7}$ do restante do país.

Na região do Cerrado baiano, especializada na produção do café tipo commodity, a estrutura produtiva apresenta-se altamente tecnificada, em grande escala de produção, porém ainda com pouca representatividade na matriz produtiva regional. A região do Planalto apresenta estrutura produtiva bastante heterogênea, abrangendo desde pequenos, médios e grandes cultivos e cafés de diversos tipos de qualidades, desde aqueles destinados exclusivamente mercado interno àqueles com mercados mais exigentes, os do tipo gourmet. O Atlântico se diferencia das demais regiões pela especialização no cultivo do café conillon, predominando pequenos e médios produtores com perfil voltado para a diversificação de atividades em torno do café.

Dadas as particularidades do atual cenário de exigências em torno da qualidade do produto cujas regulamentações têm determinado dinâmicas específicas ao longo dos segmentos produtivos, esse processo de especialização tem se colocado como forma viável de melhor posicionamento competitivo no atual cenário do mercado cafeeiro.

Estabelecida em regiões com características e aptidões bastante específicas no âmbito da cafeicultura, a atividade se desenvolveu no estado da Bahia de formas diferenciadas em cada espaço a partir da estrutura produtiva presente nas regiões do Cerrado, Planalto e Atlântico. Essas regiões têm buscado o alcance e a inserção em mercados convencionais e diferenciados, proporcionando diferentes formas de apropriação do valor gerado entre atores e regiões.

\footnotetext{
${ }^{6}$ No Brasil, denomina-se como Indicação Geográfica, a qual é regulamentada pelo Instituto Nacional da Propriedade Industrial (INPI).

${ }^{7} \mathrm{O}$ registro confirma que o Oeste tem características únicas, exclusivas, para a produção do café verde em grãos. Em pleno Cerrado, a área delimitada abrange terrenos com mais de 700 metros de altitude, com temperaturas entre 22 e 26 graus, pluviosidade média de 1.600 milímetros por ano. As áreas ficam nos municípios de Baianópolis, Barreiras, Catolândia, Cocos, Correntina, Formosa do Rio Preto, Jaborandi, Luís Eduardo Magalhães, Riachão das Neves, Santa Rita de Cássia e São Desidério.
} 


\section{Materiais e métodos}

Estudos sobre produtividade na agricultura geralmente utilizam índices para mensuração da Produtividade Total dos Fatores (PTF) através dos quais se estabelece uma relação entre os produtos e os insumos totais para definição do volume de produto a ser obtido em função de determinada combinação de insumos. Esse método permite, assim, captar, a partir do crescimento da produtividade total dos fatores, a mudança na produção, e não especificamente a mudança no volume de insumos sendo atribuída à eficiência produtiva, mudança tecnológica e erros de medição.

O conceito de produtividade total dos fatores origina-se de Solow (1957) acerca da mensuração do efeito do progresso técnico sobre o produto, utilizando na sua estimação a função de produção Cobb-Douglas para a economia norte-americana no período de 1909 a 1949. Nesse estudo, o autor identificou o "resíduo de Solow", resultante da decomposição da taxa de crescimento do produto a partir das taxas de crescimento dos fatores de produção capital e trabalho. Na literatura recente, a discussão tem se voltado para a mensuração da função de produção com enfoque nos diferenciais de produtividade e da sua evolução. Um exemplo é o trabalho de Diewert (1992), no qual se utilizam diferentes abordagens para estimação da produtividade, tanto para empresas com um produto e um insumo quanto para empresas com muitos produtos e muitos insumos.

Para mensurar a PTF em nível desagregado (lavoura de café nos municípios baianos), são necessários dados acerca do uso dos insumos terra, trabalho e capital na cafeicultura. Considerando a ausência desses dados desagregados, relativos ao uso de capital, optou-se neste estudo pela aplicação da Produtividade Parcial dos Fatores (PPF), a qual capta a variação do produto por unidade de um único fator de produção no decorrer do tempo, a preços constantes. A PPF mais abrangente utilizada para análises de produtividade é a produtividade do trabalho, na agricultura, o índice de PPF mais utilizado refere-se à produção por unidade de área (produtividade da terra). Embora as estimativas da PPF possam ser afetadas por mudanças em outros fatores, os indices de produtividade parcial constituem-se uma ferramenta que possibilita medir mudanças da produtividade ao longo do tempo, especialmente em estudos de lavouras específicas e dessa forma descrever mais detalhadamente particularidades das atividades produtivas (FAO, 2017).

A análise da produtividade da cafeicultura foi feita a partir do número de pessoas ocupadas na atividade (trabalho) e da superfície agrícola dos municípios (terra), tomando-se como variáveis de análise o valor bruto da produção de café $(\mathrm{VAB})^{8}$, o número de pessoas ocupadas na cafeicultura (L), a superfície cultivada com café (SCf) e a superfície agrícola municipal (SAg) ${ }^{9}$.

\footnotetext{
${ }^{8}$ Em todas as análises realizadas neste estudo, os valores da produção do ano de 2006 foram atualizados utilizando o deflator o Índice de Preço ao Produtor de Grupos de Produtos Agropecuários (IPPA) para o grupo que envolve os produtos cana-de-açúcar e café (IPPA-CC) divulgado pelo Centro de Estudos Avançados em Economia Aplicada (CEPEA), conforme Barros et al. (2019).

${ }^{9} \mathrm{~A}$ superfície agrícola refere-se à área total dedicada a todas as atividades agropecuárias nos muni-
} 
Os dados referentes à cafeicultura foram extraídos dos Censos Agropecuários de 2006 e 2017, através do Sistema IBGE de Recuperação Automática (SIDRA), abrangendo 212 municípios ${ }^{10}$ que fazem parte das microrregiões baianas dedicadas a essa atividade produtiva, o que permitiu realizar uma análise comparativa da produtividade do trabalho e da terra da cafeicultura no estado da Bahia.

As zonas consideradas na análise deste trabalho tomam como referência as informações agroclimáticas e geográficas da Companhia Nacional de Abastecimento (CO$\mathrm{NAB}, 2014)$, as quais consideram três áreas aptas à cafeicultura na Bahia. Essas zonas são denominadas: Cerrado, que compreende as microrregiões de Barreiras, Santa Maria da Vitória e Cotegipe; Planalto, que abrange as microrregiões de Boquira, Seabra, Jequié, Livramento do Brumado, Guanambi, Brumado, Vitória da Conquista e Itapetinga; e Atlântico, que alcança as microrregiões de Porto Seguro, Ilhéus-Itabuna e Valença, envolvendo um total e 212 municípios.

A partir das Fórmulas 1 e 2, observa-se o comportamento das variáveis selecionadas, analisando a produtividade da cafeicultura a partir do emprego (trabalho) e da área agrícola (terra) dos municípios baianos, considerando-se a relação entre Valor bruto da produção de café (VAB), Número de pessoas ocupadas na cafeicultura (L), Superfície cultivada com café (SCf) e Superfície Agrícola Municipal (SAg) agregadas por municípios no estado da Bahia.

A produtividade do trabalho se relaciona com a produtividade da terra, expressa pela identidade $V A B / L=V A B / S C f+S C f / L$, em que VAB representa a renda bruta obtida na cafeicultura, L o número de pessoas empregadas na atividade e SCf a área cultivada com café. O termo $(V A B / L)$ refere-se à produtividade do trabalho obtida pelo emprego direto das variáveis. O termo $(V A B / S C f)$ diz respeito à produtividade da terra, influenciada por tecnologias poupadoras do seu uso, como fertilizantes, por exemplo. O termo $(S C f / L)$ constiui-se uma outra medida da produtividade do trabalho, a partir da área que cada trabalhador é capaz de cultivar, influenciada pelos índices de mecanização, representando, dessa forma, a capacidade de o trabalhador cultivar a área disponível.

Dessa forma, ocorre a relação principal entre as variáveis VAB e L que estimam a produtividade do trabalho na cafeicultura a partir da distribuição do valor da produção (VAB) por pessoas ocupadas na atividade (L), pela decomposição em dois termos: $V A B / S C f$ e $S C f / L$, a partir da seguinte fórmula:

$$
\frac{V A B}{L}=\frac{V A B}{S C f} \frac{S C f}{L}
$$

sendo, $V A B / L$ : produtividade por pessoa ocupada na cafeicultura; $V A B / S C f$ : produtividade por área plantada com café; $S C f / L$ : área plantada por pessoa ocupada na

\footnotetext{
cípios.

${ }^{10}$ Cabe destacar que não houve criação de novos municípios entre os Censos de 2006 e 2017.
} 
cafeicultura.

Da mesma maneira, a análise da produtividade da terra na cafeicultura a partir da área agrícola dos municípios considerou a relação entre Valor bruto da produção de café (VAB), Superfície agrícola (SAg) e Superfície cultivada com café (SCf) agregados por municípios no estado da Bahia.

Assim, a relação principal entre as variáveis VAB e SAg que mensura a produtividade da cafeicultura a partir da distribuição do valor da produção (VAB) por superfície agrícola dos municípios (SAg) foi reescrita em outros dois componentes: $V A B / S C f \mathrm{e}$ $S C f / S A g$, cuja estimação foi realizada a partir seguinte identidade:

$$
\frac{V A B}{S A g}=\frac{V A B}{S C f} \frac{S C f}{S A g}
$$

sendo, $V A B / S A g$ : produtividade da cafeicultura em relação à área agrícola; $V A B / S C f$ : produtividade por área plantada com café; $S C f / S A f$ : área plantada com café em relação à área agrícola.

\section{Resultados e discussão}

Conforme Tabela 5, nota-se redução nos valores absolutos da maior parte das variáveis analisadas no estado da Bahia, exceto para a superfície cultivada com café que apresentou crescimento de 4,0\% entre os anos censitários de 2006 e 2017. Das reduções observadas, a mais expressiva ocorreu no número de pessoas ocupadas na atividade, 59,7\%, destacando-se o Atlântico que apresentou a maior redução entre as regiões em análise, apesar de aumento para as demais variáveis.

De maneira geral, tal cenário pode indicar que, em situação de aumento da área plantada e diminuição do número de pessoas ocupadas, o cultivo de café torna-se cada vez menos intensivo no uso do trabalho. A despeito da redução na maior parte das variáveis, a área cultivada com café aumentou, embora esse acréscimo não tenha sido suficiente para reverter a queda da produção cafeeira no período.

Observando os dados desagregados por região cafeeira, verificam-se o aumento da área cultivada com café nas regiões do Cerrado e do Atlântico e o aumento mais expressivo no valor da produção a despeito da maior redução no pessoal ocupado entre os niveis regionais estudados. Nesse contexto, a análise da produtividade do trabalho e da terra na cafeicultura baiana revela aspectos específicos da atividade cafeeira no estado.

A produtividade do trabalho na cafeicultura, calculada a partir da relação $V A B / L$, representada na Figura 3, aponta que, no ano de 2006, as zonas produtoras do Cerrado e do Atlântico concentraram maior valor da produção por pessoa empregada na cafeicultura em relação à região do Planalto. Essa situação mantém-se na região do 
Cerrado, porém se altera na região do Atlântico no ano de 2017.

Tabela 5. Valor agregado das variáveis analisadas, por regiões cafeeiras e Bahia, 2006 e 2017

\begin{tabular}{llrrrr}
\hline \hline Ano & Região & VAB (R\$) & SCf (ha) & SAg (ha) & L (pessoas) \\
\hline \multirow{2}{*}{2006} & Cerrado & $143.153 .241,46$ & 12.135 & 6.472 .980 & 3.667 \\
& Planalto & $361.179 .643,97$ & 77.911 & 6.885 .213 & 69.631 \\
& Atlântico & $157.318 .327,87$ & 24.039 & 3.874 .286 & 8.270 \\
& Demais regiões & $96.478 .653,90$ & 7.638 & 12.349 .275 & 7.349 \\
& Bahia & $758.129 .867,20$ & 121.723 & 29.581 .754 & 88.917 \\
\hline \multirow{3}{*}{2017} & Cerrado & $176.451 .000,00$ & 13.968 & 6.956 .388 & 599 \\
& Planalto & $176.247 .352,20$ & 65.191 & 6.462 .096 & 32.807 \\
& Atlântico & $396.623 .000,00$ & 42.923 & 3.900 .300 & 31 \\
& Demais regiões & $6.188 .000,00$ & 4.463 & 10.702 .071 & 2.405 \\
& Bahia & $755.509 .352,20$ & 126.545 & 28.020 .855 & 35.842 \\
\hline \multirow{2}{*}{ Taxa de } & Cerrado & $23,3 \%$ & $15,1 \%$ & $7,5 \%$ & $-83,7 \%$ \\
crescimento & Planalto & $-51,2 \%$ & $-16,3 \%$ & $-6,1 \%$ & $-52,9 \%$ \\
$2006-2017$ & Atlântico & $152,1 \%$ & $78,6 \%$ & $0,7 \%$ & $-99,6 \%$ \\
\cline { 2 - 5 } & Demais regiões & $-93,6 \%$ & $-41,6 \%$ & $-13,3 \%$ & $-67,3 \%$ \\
& Bahia & $-0,3 \%$ & $4,0 \%$ & $-5,3 \%$ & $-59,7 \%$ \\
\hline \hline
\end{tabular}

Nota: Valor bruto da produção de café (VAB), superfície cultivada com café (SCf), superfície agrícola municipal (SAg) e número de pessoas ocupadas na cafeicultura (L). Fonte: Elaboração própria com base nos dados dos Censos Agropecuários de 2006 e 2017 (IBGE, 2006, 2017).

As distintas regiões com café na Bahia se diferenciam em relação à forma de ocupação da mão de obra (trabalho) e ao tamanho das unidades de produção (uso da terra). Enquanto na região do Planalto predominam pequenas áreas e mão de obra do tipo familiar, no Cerrado as áreas produtivas são mais extensas e mais intensivas em capital e, portanto, com número menor de pessoas. Isso reflete a apropriação do valor gerado e a forma de ocupação de mão de obra (trabalho) na atividade. Além disso, essa relação é uma medida que permite inferências sobre a dinâmica distributiva da atividade nas regiões produtoras de café na Bahia.

O termo $V A B / S C f$, conforme Figura 4, revela, no ano de 2006, maior concentração da renda por área cultivada com café em alguns municípios do Planalto. Observando a escala de valores calculados que apresenta valor mínimo de $\mathrm{R} \$ 3.451,48$ e máximo de $\mathrm{R} \$ 2.396 .960,19$ reais por hectare, destacam-se, em tons de azul, os municípios Urandi $(2.396 .960,19)$, Tanque Novo $(654.025,47)$, Wagner $(371.491,91)$, 
Paramirim (237.214,81), Novo Horizonte (205.571,02), Mortugaba (97.010,92), Jequié (54.458,62), Poções (28.939,71), Nova Redenção $(27.360,48)$, Igaporã $(12.465,71)$, Rio de Contas $(10.336,52)$, Jussiape $(8.947,37)$, Cravolândia $(8.178,45)$, Piripá $(7.693,82)$ e Ibicoara (7.620,08), que juntos exploram 5.729 hectares, 7\% do total de área cultivada com café (SCf) do Planalto.

Figura 3. Análise da produtividade do trabalho na cafeicultura baiana em função do número de pessoas empregadas na atividade, relação VAB/L, 2006 e 2017
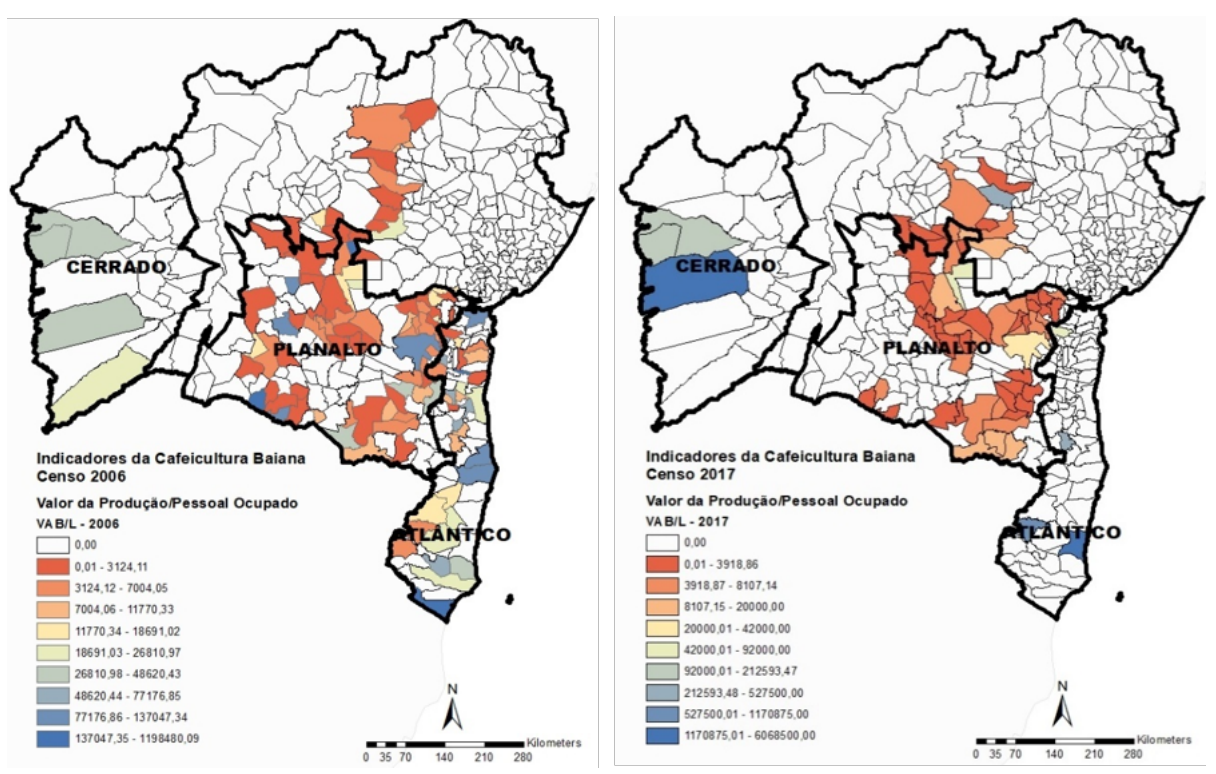

Fonte: Elaboração própria com base nos dados dos Censos Agropecuários de 2006 e 2017 (IBGE, 2006 , 2017).

Figura 4. Análise da produtividade do trabalho na cafeicultura baiana em função do número de pessoas empregadas na atividade, termo $V A B / S C f, 2006$ e 2017
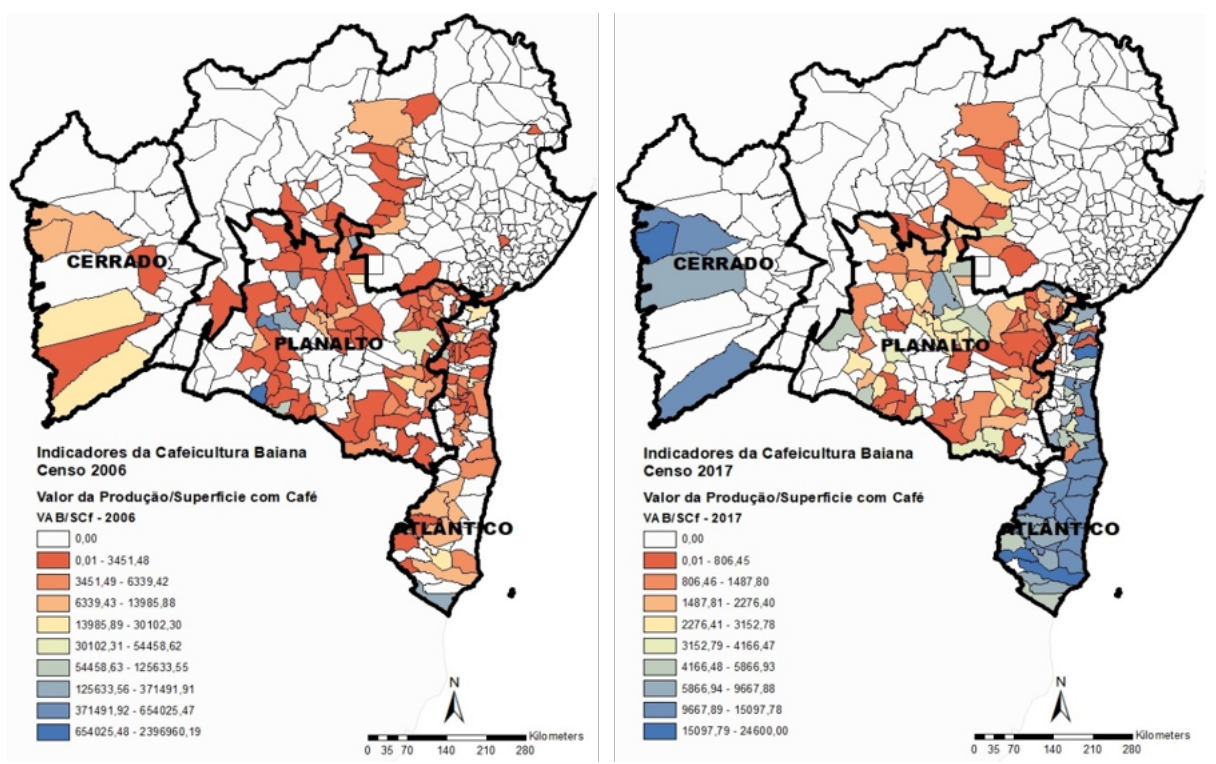

Fonte: Elaboração própria com base nos dados dos Censos Agropecuários de 2006 e 2017 (IBGE, 2006, 2017). 
Figura 5. Análise da produtividade da cafeicultura baiana em função do número de pessoas empregadas na atividade, termo $S C f / L, 2006$ e 2017

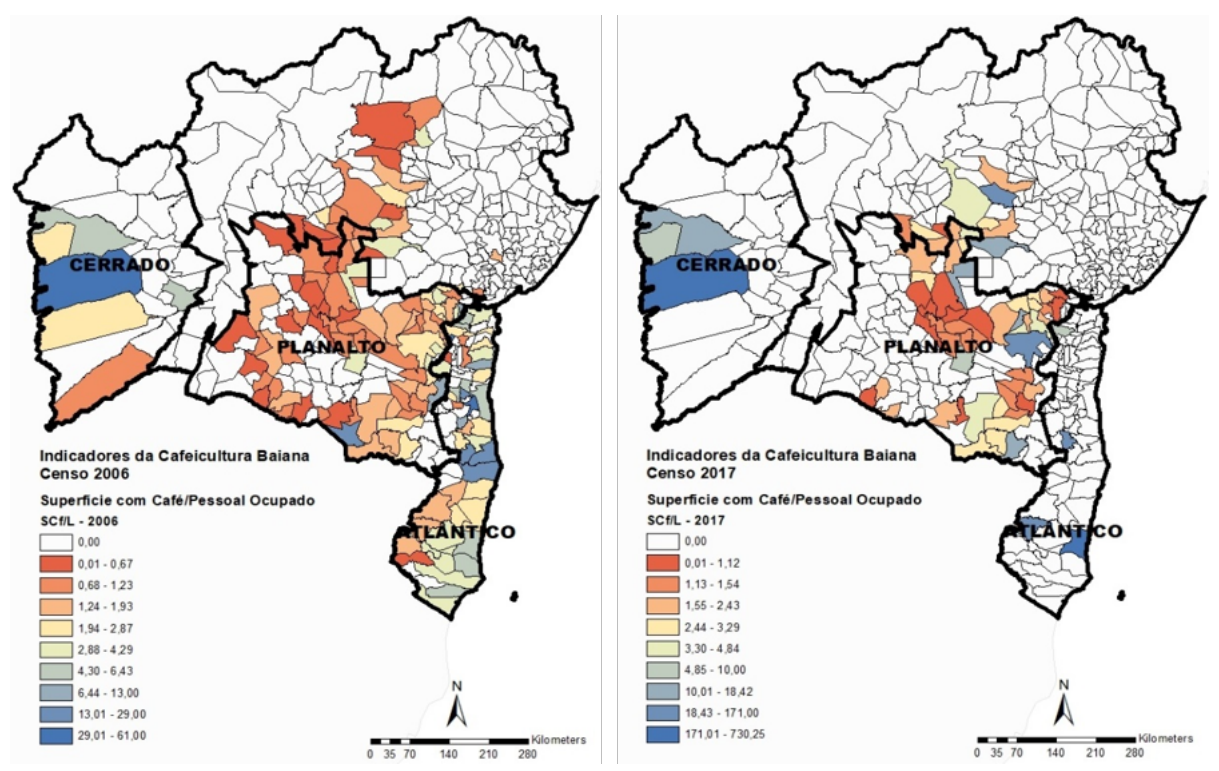

Fonte: Elaboração própria com base nos dados dos Censos Agropecuários de 2006 e 2017 (IBGE, 2006, 2017).

É interessante destacar que cinco entre esses 15 municípios pertencem à região da Chapada Diamantina, onde os cafés especiais vêm expandido a comercialização. No Atlântico, destacam-se Mucuri $(204.132,74)$, Ipiaú $(125.633,55)$, Uruçuca $(47.502,50)$, Valença (30.102,30), Teixeira de Freitas (23.877,07), Gandu (17.876,32), Coaraci (10, $507,29)$, Guaratinga $(10.251,45)$, Eunápolis $(9.269,65)$, e Itabela $(9.114,67)$ que juntos exploram 5.050 hectares, ou seja, $21 \%$ da área cultivada com café (SCf) dessa região. Nota-se, em 2017, maior concentração do VAB por hectare cultivado com café em toda a região do Cerrado e Atlântico, podendo ser resultado tanto de aumento do rendimento da produção física por hectare quanto do melhor desempenho em mercados específicos que agregam maior valor ao produto.

O termo $S C f / L$, representado na Figura 5, demonstra o tamanho da área cultivada com café (em hectares) por pessoa ocupada na atividade.

Esse termo, apresenta-se como um indicativo de concentração de área cultivada com café entre as regiões, revelando que, no ano de 2006, as maiores proporções de área por pessoa ocupada na cafeicultura baiana estão nas regiões do Cerrado e do Atlântico, em relação ao Planalto. No ano de 2017, verifica-se maior quantidade de municípios com $S C f$ igual a zero (manchas brancas) em todas as regiões cafeeiras da Bahia e aumento da concentração da área cultivada com café por pessoa ocupada na atividade, indicando redução da área cultivada com café, o que pode estar relacionado com a redução de pessoas ocupadas na atividade conforme dados descritos na Tabela 5.

Tal fenômeno pode estar relacionado com uma maior concentração da atividade 
dado o nível tecnológico e consequente independência em relação ao uso do fator trabalho e também com o abandono da atividade pela substituição por lavouras mais lucrativas ou pela concorrência com lavouras mais intensivas em capital.

A produtividade da terra na cafeicultura, calculada a partir da relação $V A B / S A g$ e representada na Figura 6, reflete uma medida de especialização dos municípios em relação à cafeicultura. Portanto, a Figura 6 permite detectar uma situação inversa ao verificado na análise por pessoal ocupado, ao analisarmos o cenário regional em 2006: a zona produtora do Planalto possui uma relação de rendimentos com café por área agrícola relativamente superior à das regiões do Cerrado e do Atlântico, indicando que alguns dos seus municípios têm maior dependência da cafeicultura do que aqueles localizados nas demais regiões.

Figura 6. Análise da produtividade da terra na cafeicultura baiana em função da superfície agrícola dos municípios, relação $V A B / S A g, 2006$ e 2017
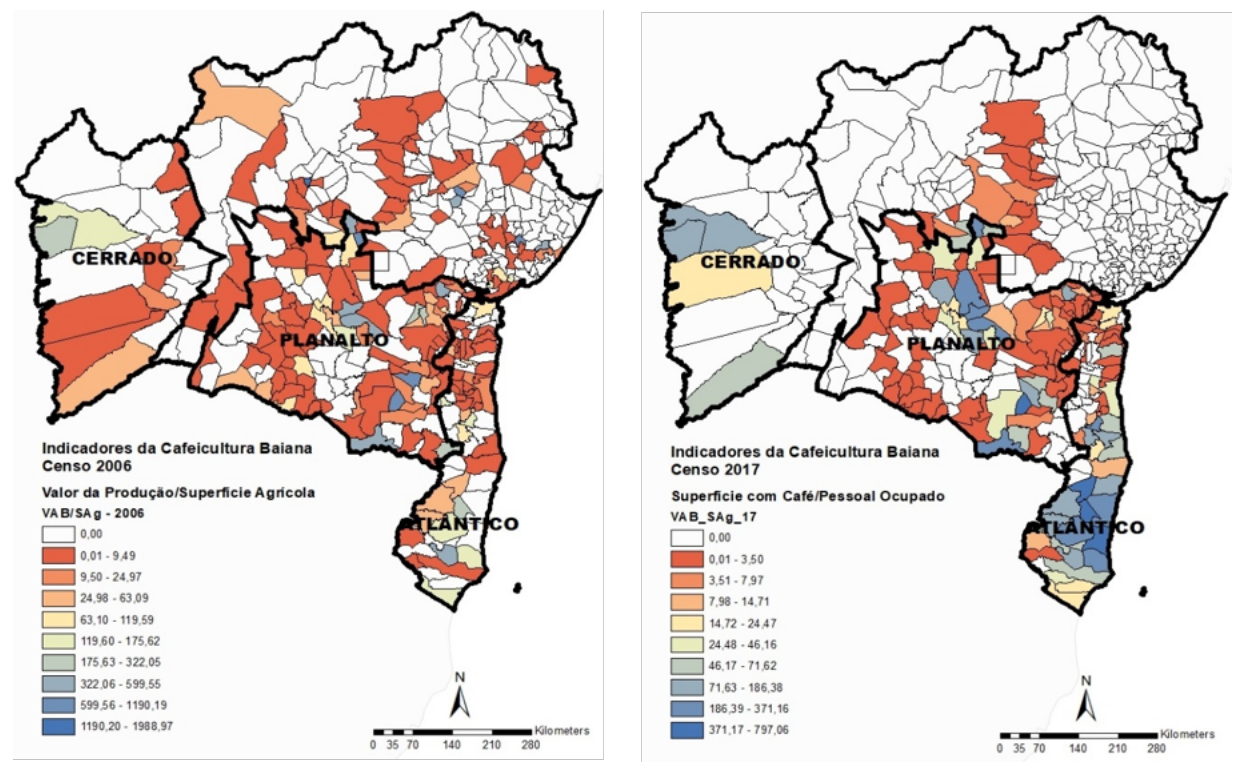

Fonte: Elaboração própria com base nos dados dos Censos Agropecuários de 2006 e 2017 (IBGE, 2006, 2017).

No ano de 2017, verificam-se novamente municípios com VAB igual a zero (manchas brancas) especialmente no Cerrado e Planalto, destacando-se a visível ampliação da concentração do VAB por hectare de área agrícola em toda a região do Atlântico e do Cerrado, destacando-se em relação ao Planalto.

O termo $V A B / S C f$, conforme a Figura 7, reforça o exposto na Figura 6, salientando também maior concentração da renda por área cultivada com café em poucos municípios do Planalto e do Atlântico, no ano de 2006.

Ao analisar o termo $V A B / S C f$ no contexto da produtividade da terra na cafeicultura, reforça-se a ideia de que a região do Cerrado concentrou maior parcela da renda do que as demais no ano de 2006, situação que se altera no ano de 2017 em favor das 
regiões do Cerrado e do Atlântico. Tal fato retrata o abandono da atividade cafeeira em municípios do Cerrado e do Planalto (manchas brancas) e o avanço do cultivo no Atlântico.

Figura 7. Análise da produtividade da terra na cafeicultura baiana em função da superfície agrícola dos municípios, termo $V A B / S C f$, 2006 e 2017
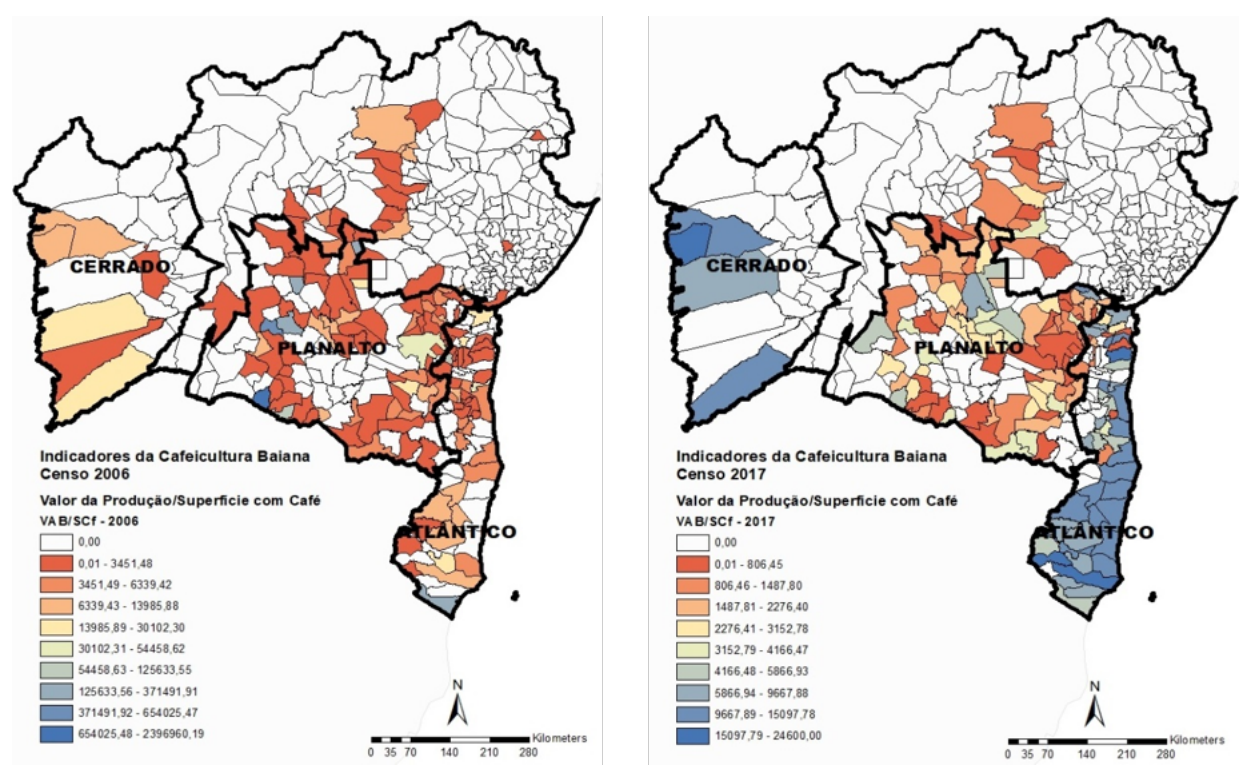

Fonte: Elaboração própria com base nos dados dos Censos Agropecuários de 2006 e 2017 (IBGE, 2006 , 2017).

O termo $S C f / S A g$ que indica a concentração na atividade cafeeira está representado na Figura 8.

A análise desse termo demonstrou, para o ano de 2006, menor concentração de área plantada com café por área agricultável e maior especialização na cafeicultura em municípios localizados na região do Planalto em relação às demais.

No ano de 2017, em diversos municípios das regiões do Cerrado e do Planalto, amplia-se a especialização na cafeicultura, especialmente em municípios do Planalto de Vitória da Conquista e da Chapada Diamantina, assim como ocorreu em grande parte do Atlântico.

Na Tabela 6, verificam-se as taxas de crescimento da produtividade da terra e do trabalho por região.

Observa-se que o Atlântico se destaca, por elevadas e positivas taxas de produtividade, distintamente do Planalto que apresenta taxas negativas, exceção para o valor da produção e a área cultivada com café por pessoa ocupada na atividade, que apresentaram crescimento de $15 \%$ e $98 \%$, respectivamente. Destaca-se que o $V A B / L$ e a $S C f / L$ apresentaram taxas de crescimento positivas em todas as regiões. 
Figura 8. Análise da produtividade da terra na cafeicultura baiana em função da superfície agrícola dos municípios, termo $S C f / S A g, 2006$ e 2017
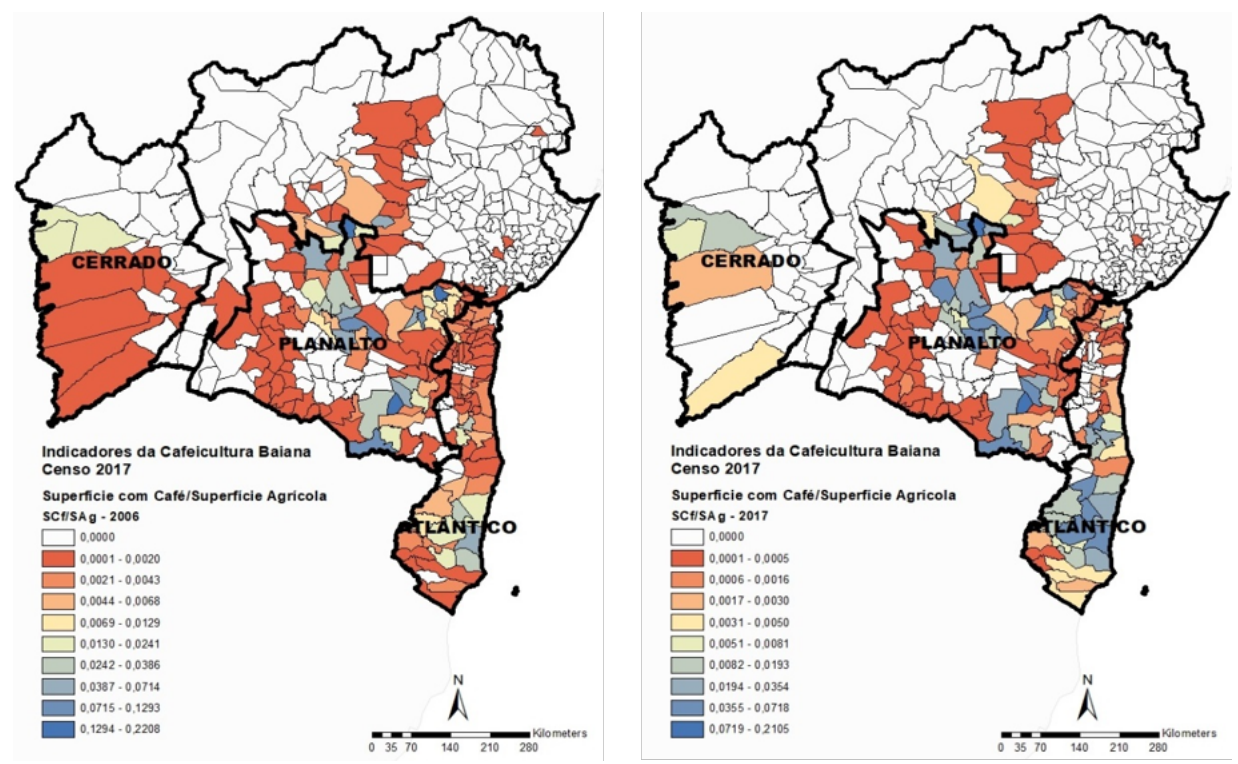

Fonte: Elaboração própria com base nos dados dos Censos Agropecuários de 2006 e 2017 (IBGE, 2006, 2017).

De forma geral, a partir das análises realizadas, observa-se que o Cerrado possui maior concentração relativa no que se refere à apropriação da renda gerada na atividade, apesar da redução da produtividade do trabalho $(V A B / L)$ nos municípios de Cocos e Correntina, no período analisado, o que pode ser explicado pela sua estrutura fundiária altamente concentrada bem como pela redução relativa da área cultivada $(S C f / S A g)$ com café no período. Portanto, infere-se que, pelo fato de possuir estrutura intensiva em capital e matriz produtiva agrícola diversificada, voltada ao setor exportador, essa região tem mais possibilidades de compatibilizar o uso dos fatores ao reduzir a dependência do fator trabalho e diversificar alternativas de uso do fator terra, o que permite potencializar a produtividade desses. Dessa forma, os resultados específicos para a cafeicultura nessa região indicam o quanto esta atividade representou uma alternativa favorável à alocação desses recursos para a produção de café arábica tipo commodity no período em estudo.

A região do Planalto, por sua vez, possui uma estrutura produtiva diversa, distribuída entre uma menor parte de grandes propriedades mais intensivas em capital e uma maioria de minifúndios de produção tradicional. Essa região possui maior dependência relativa do fator trabalho e foi a mais afetada pela sua redução do período analisado, dada a menor intensidade tecnológica capaz de compensar essa redução. A estratégia regional nessa área reside na dinâmica de inserção nos mercados específicos, de cafés especiais, que valorizam a produção artesanal do café arábica, o que atribui maior qualidade ao produto final. Nesse sentido, a maior valorização do produto pela sua qualidade contribui para compensar as oscilações na produtividade dos fatores no Planalto cafeeiro baiano. 
Tabela 6. Taxa de crescimento da produtividade do trabalho e da terra por região cafeeira do estado da Bahia entre os anos de 2006 e 2017

\begin{tabular}{lrrrrr}
\hline \hline Região & VAB/L & VAB/Scf & Scf/L & VAB/SAg & Scf/SAg \\
\hline CERRADO & $485 \%$ & $7 \%$ & $447 \%$ & $15 \%$ & $7 \%$ \\
PLANALTO & $15 \%$ & $-42 \%$ & $98 \%$ & $-48 \%$ & $-11 \%$ \\
ATLÂNTICO & $579 \%$ & $41 \%$ & $381 \%$ & $150 \%$ & $77 \%$ \\
\hline \hline
\end{tabular}

Fonte: Elaboração própria com base nos dados dos Censos Agropecuários de 2006 e 2017 (IBGE, 2006, 2017).

No Atlântico, tem-se uma estrutura produtiva relativamente mais homogênea, distribuída em uma maioria de médias e pequenas propriedades com maior intensidade tecnológica. Além disso, explora-se um mercado diferente das outras regiões, voltado à comercialização do café conillon, menos valorizado quanto à qualidade, em relação ao arábica. Entretanto, apesar de ter experimentado a maior redução no número de pessoas ocupadas $(-99,6 \%)$ em relação às outras regiões, foi capaz de ampliar a produtividade dos fatores no período, tendo apresentado uma elevada taxa de ampliação da área cultivada com café $(78,6 \%)$. Isso refletiu o crescimento de $579 \%$ na produtividade do trabalho $(V A B / L)$ e de $150 \%$ na produtividade da terra $(V A B / S A g)$ na atividade cafeeira baiana.

\section{Considerações finais}

A análise revela redução de pessoal ocupado na cafeicultura baiana entre os anos 2006 e 2017, embora tenha ampliado a concentração dos resultados financeiros por pessoa ocupada na atividade nas regiões do Cerrado e Atlântico em detrimento da região do Planalto.

No Cerrado, predomina um segmento de produtores com intensivo uso de tecnologia na lavoura; no Atlântico, médios produtores e relativamente capitalizados; e, no Planalto, uma grande maioria de pequenos produtores descapitalizados. Essas distinções geram diferenças substanciais na atividade cafeeira dessas regiões, pois muitas vezes há abandono da atividade em função da falta de capital que propicie maiores índices de produtividade, o que também, em contrapartida, afeta diretamente a redução do fator trabalho nessa lavoura.

A análise da produtividade da terra revela pequeno aumento da superfície cultivada com café nos anos censitários analisados, porém com concentração da atividade, especialmente na região do Atlântico.

A renda gerada na cafeicultura, por pessoa ocupada, é maior no Cerrado, haja vista que essa região apresenta os maiores índices de produtividade em função da presença 
de unidades produtivas mais intensivas em tecnologia. Por outro lado, quando se analisa a relevância da atividade em termos de área agricultável dos municípios, sobressaem as regiões do Planalto e do Atlântico, tendo esta última ampliado a produtividade da terra no período analisado em detrimento da retração ocorrida no Planalto.

Os resultados alcançados permitem constatar que em 10 anos a cafeicultura baiana experimentou transformações, tornando-se mais concentrada e intensiva em capital, refletida na intensa redução do fator trabalho na atividade. Esse fenômeno tem efeitos importantes sobre a cafeicultura familiar, a qual é ainda o modelo predominante no cenário baiano, principalmente na região do Planalto, visto que, nos moldes de produção atual, muitos produtores têm abandonado a atividade e aqueles que permanecem buscam adotar estratégias de diferenciação e inserção do produto em novos nichos de mercado.

A agregação de maior valor ao produto pode se constituir em estratégia-chave para a pequena escala produtiva, através da incorporação de elementos intangiveis ao sistema produtivo, desde a valorização da localização da produção até as formas de processamento, que podem refletir as singularidades locais, as quais têm sido muito valorizadas em mercados específicos. Nesse contexto, a produção de café na zona do Planalto, mais especificamente na região da Chapada Diamantina, tem buscado se adentrar no mercado de cafés especiais, essa estratégia pode levá-la a se tornar referência no Brasil, quiçá em nível mundial.

Os instrumentos metodológicos utilizados neste trabalho para discutir a produtividade da cafeicultura baiana possibilitaram compreender espacialmente o comportamento da atividade cafeeira a partir do emprego gerado e da área agrícola destinada à produção. Tais elementos evidenciam um caráter heterogêneo e dicotômico entre as regiões baianas produtoras de café.

Por um lado, a região do Atlântico, cuja estrutura fundiária está delineada em pequenas e médias propriedades relativamente capitalizadas, vem adotando estratégias de ampliação dos cultivos e da produtividade ao longo do tempo. Por outro lado, a região do Cerrado apresenta alta concentração fundiária e intensidade tecnológica, enquanto a do Planalto se caracteriza por produtores menos capitalizados, médios e grandes, como também pela maior presença de minifúndios descapitalizados. Tais diferenças, diante das oscilações do mercado de commodities, têm levado produtores a enfrentar novos desafios de adaptação a esse cenário, com consequências diversas sobre a configuração espacial da atividade no estado da Bahia.

O cenário heterogêneo da cafeicultura baiana representa desafios aos produtores e órgãos de fomento à atividade bem como oportunidades de inserção nas vastas possibilidades que o mercado cafeeiro proporciona.

Em uma perspectiva de médio e longo prazos, a qualidade do produto deverá se apresentar como principal fator de concorrência e os produtores do Planalto têm como desafio ampliar o uso de tecnologias adaptadas à heterogênea escala de produção de 
seus cafeicultores alcançando resultados mais próximos das regiões do Cerrado e do Atlântico no que se refere à adequação em um cenário de escassez do fator trabalho.

Sugere-se, a partir do exposto, realizar uma avaliação espacial para verificar a formação de clusters espaciais de produtividade e de seus componentes e aplicar outras estratégias metodológicas que permitam estimar os componentes que podem afetar a estrutura espacial da cafeicultura baiana.

\section{Referências}

Anh, N. H., Bokelmann, W., Van Minh, N., et al. (2019). Toward sustainability or efficiency: The case of smallholder coffee farmers in vietnam. Economies, 7(3):1-25.

Barros, P. H. B. d., Oliveira, R. A. d., e Baggio, I. S. (2019). Coffee productivity and regional development in Brazil. Revista de Política Agrícola, 28(2):76-92.

Bernardes, R. S. (2019). Análise espacial da produtividade de café em Minas Gerais (2002-2017). Dissertação (Mestrado em Estatística Aplicada e Biometria). Universidade Federal de Alfenas.

Cardozo, D. P., Las Schaab, L., e Parré, J. L. (2019). Análise espacial da produtividade do café na região Sudeste do Brasil: 1990-2015. Revista Economia Ensaios, 34(1):176-198.

CONAB (2014). Acompanhamento da safra brasileira - café. Brasília: Companhia Nacional de Abastecimento (CONAB).

Diewert, W. E. (1992). The measurement of productivity. Bulletin of Economic Research, 44(3):163-198.

FAO (2017). Productivity and efficiency measurement in agriculture: literature review and gaps analysis. Organização das Nações Unidas para Agricultura e Alimentação.

Fernandes, R. H. (2014). Diagnóstico e propostas para a cadeia produtiva do café da Bahia. Secretaria da Agricultura, Irrigação e Reforma Agrária.

Ferrão, R. G., Galeano, E. A. V., Taques, R. C., e Souza, R. C. (2019). Mudança na distribuição espacial da produtividade da cafeicultura no espírito santo nos anos 2011-2016. Multi-Science Research, 2(1):88-112.

IBGE (2006). Censo Agropecuário 2006. Instituto Brasileiro de Geografia e Estatística.

IBGE (2016). A geografia do café: dinâmica territorial da produção agropecuária. Instituto Brasileiro de Geografia e Estatística.

IBGE (2017). Censo Agropecuário 2017. Instituto Brasileiro de Geografia e Estatística.

Moreira, P. C., Moreira, G. C., Castro, N. R., e da Silva, R. P. (2019). Produtividade e economia de fatores de produção na cafeicultura brasileira. Revista de Politica Agrícola, 28(2):6-32. 
Nchare, A. (2007). Analysis of factors affecting the technical efficiency of arabica coffee producers in Cameroon. AERC Research Paper, n. 163. African Economic Research Consortium (AERC).

Neto, E. (2010). Arabica x Robusta: quando dois mundos se encontram. Café Point Mercado.

Ngango, J. e Kim, S. G. (2019). Assessment of technical efficiency and its potential determinants among small-scale coffee farmers in Rwanda. Agriculture, 9(7):161182.

Nurhapsa, N., Nuddin, A., Suherman, S., e Barbara, B. (2020). Is input utilization inelastic to coffee production. International Journal of Agriculture System, 8(1):2633.

Ormond, J. G. P., Paula, S. R. L. d., e Faveret Filho, P. d. S. C. (1999). Café:(re) conquista dos mercados. Banco Nacional de Desenvolvimento Econômico e Social.

Prasad, K. A., Suman, K., Prakash, D. J., Chandra, D. S., e Ram, K. R. (2019). An assessment of factors determining the productivity of coffee in western hills of Nepal. International Journal of Agricultural Sciences and Veterinary Medicine, 7(2):11-17.

Saes, M. S. M. e Nakazone, D. (2002). Estudo da competitividade de cadeias integradas no Brasil: impactos das zonas de livre comércio. Cadeia: Café. Campinas: Universidade Estadual de Campinas.

Silva, G. R. (2013). Caracterização da notoriedade do café do planalto de Vitória da Conquista-BA, para a indicação geográfica de procedência. VIII Simpósio de Pesquisa dos Cafés do Brasil, 2013, Salvador, Bahia.

Solow, R. M. (1957). Technical change and the aggregate production function. The review of Economics and Statistics, 39(3):312-320.

Temesgen, A. e Tufa, A. (2017). Analysis of coffee farm productivity in Darolabu District, West Hararghe Zone, Ethiopia. American Journal of Environmental and Resource Economics, 2(4):158-161.

Volsi, B., Telles, T. S., Caldarelli, C. E., e Camara, M. R. G. d. (2019). The dynamics of coffee production in Brazil. PloS One, 14(7):e0219742.

Wollni, M. e Brümmer, B. (2012). Productive efficiency of specialty and conventional coffee farmers in costa rica: Accounting for technological heterogeneity and selfselection. Food Policy, 37(1):67-76.

@Ev Este artigo está licenciado com uma CC BY 4.0 license. 